\title{
Bullying e Educação Física escolar: uma revisão da produção científica
}

\author{
Bullying and school Physical Education: a review of scientific production \\ Bullying y educación física escolar: una revisión de la producción científica \\ Fabiano Fuchs ${ }^{\mathrm{I}}$, Alexandra Folle ${ }^{\mathrm{II}}$, Larissa Cerignoni Benites ${ }^{\mathrm{III}}$ Viviane Preichardt Duek ${ }^{\mathrm{IV}}$
}

\begin{abstract}
Resumo
O estudo objetivou revisar artigos originais sobre bullying nas aulas de Educação Física. As bases de dados consultadas foram: Lilacs, Scielo, Medline/EBSCO, Scopus, SPORTDiscus e Web of Science. Foram selecionados 12 artigos publicados entre os anos de 2010 e 2015. Os resultados indicam que a vitimização por bullying aparece associada a indivíduos com habilidades motoras limitadas, baixo desempenho motor e menor participação nas aulas de Educação Física. Evidencia-se, assim, a necessidade de realização de estudos de aprofundamento sobre o bullying e suas manifestações no contexto escolar, particularmente, nas aulas de Educação Física.
\end{abstract}

Palavras-chave: Bullying; Violência; Educação Física; Escola

\begin{abstract}
The study aimed to review original articles on bullying in Physical Education classes. The databases consulted were: Lilacs, Scielo, Medline/EBSCO, Scopus, SPORTDiscus and Web of Science. We selected twelve articles published between 2010 and 2015. The results indicate that bullying victimization appears to be associated to individuals with limited motor skills, poor performance and lower participation in Physical Education classes. Thus, it is necessary to carry out in-depth studies on bullying and its manifestations in the school context, particularly in Physical Education classes.
\end{abstract}

Key words: Bullying; Violence; Physical Education; School

\footnotetext{
I Secretaria Municipal de Educação de Florianópolis-SC - Rua Conselheiro Mafra, nº 656 - 5 Andar - Sala 502 Centro - CEP: $88010-914$ - e-mail: fabianofuchsff@gmail.com

II Universidade do Estado de Santa Catarina - UDESC - e-mail: afolle_12@hotmail.com

III Universidade do Estado de Santa Catarina - UDESC - e-mail: lari.benites@ gmail.com

IV Universidade do Estado de Santa Catarina - UDESC - e-mail: vividuek@ hotmail.com
} 


\section{Resumen}

El objetivo del estudio fue revisar los artículos originales sobre el bullying escolar en las clases de educación física. Las bases de datos consultadas fueron: Lilacs, Scielo, Medline/EBSCO, Scopus, SPORTDiscus y Web of Science. Seleccionamos 12 artículos publicados entre 2010 y 2015. Los resultados indican que la victimización por bullying parece estar asociada a personas con habilidades motoras limitadas, bajo rendimiento motor y menor participación en las clases de educación física. Por lo tanto, es necesario llevar a cabo estudios en profundidad sobre el bullying y sus manifestaciones en el contexto escolar, particularmente en las clases de educación física.

Palabras clave: Bullying; Violencia; Educación Física; Escuela

\section{Introdução}

A violência nas escolas configura-se fenômeno antigo, provavelmente tão remoto quanto a própria escola, mas que, somente nas últimas décadas, passou a ser reconhecida como problemática que desencadeia uma série de prejuízos ao desenvolvimento escolar e social dos envolvidos (OLIVEIRA et al., 2015; FANTE, 2005; ALMEIDA; CARDOSO; COSTAC, 2009). Segundo Sposito (2001), entre as décadas de 1980 e 1990, houve aumento da preocupação com a violência escolar, relacionada, inicialmente, à depredação das instituições de ensino e, posteriormente, entre o fim dos anos de 1990 e início dos anos de 2000, às relações agressivas entre os indivíduos dentro do ambiente escolar. De acordo com Lopes Neto (2005), o termo "violência escolar" refere-se a qualquer tipo de conduta agressiva e antissocial, manifestada através de conflitos interpessoais, de atos criminosos ou, ainda, da depredação do patrimônio das instituições.

Um tipo de violência crescente, difundindo-se e alcançando patamares preocupantes, é o fenômeno bullying ${ }^{1}$ Através de comportamentos deliberados e danosos, o bullying ${ }^{2}$. corresponde a uma série de atitudes agressivas, intencionais e repetitivas, praticadas por um ou mais alunos e têm os ataques concentrados a outro(s). Nesse sentido, o bullying apresenta um desequilíbrio de poder entre o agressor e a vítima que, em geral, não dispõe de recursos, status ou habilidade para reagir ou romper com tal situação (FANTE, 2005; ALMEIDA; SILVA; CAMPOS, 2008; BOTELHO; SOUZA, 2007; LOPES NETO, 2005).

O bullying manifesta-se por duas formas: direta e indireta. A direta pode englobar agressões físicas como bater, empurrar, roubar pertences; e/ou agressões verbais como discriminar, constranger e

\footnotetext{
1 Termo sem tradução em português.

2 Bullying é uma palavra de origem inglesa, utilizada em vários países, pela literatura psicológica anglo-saxônica, para conceituar o desejo de maltratar outra pessoa. Entretanto, somente na década de 1970, primeiramente na Suécia, a sociedade passou a se interessar pela problemática, e o bullying passa a ser objeto de estudo sistemático (FANTE, 2005; SILVA, 2010).
} 
insultar. A forma indireta é possivelmente a mais prejudicial, e se materializa através de indiferença, difamação, fofocas, discriminação e isolamento, podendo resultar em exclusão de um determinado grupo social (FANTE, 2005).

No tocante à atitude adotada nas situações de bullying, os estudantes podem ser identificados enquanto agressor, vítima, vítima agressora e testemunha. $\mathrm{O}$ agressor costuma ser um indivíduo (ou um grupo) de pouca empatia, além de comumente dispor de maior força física e, principalmente entre os meninos, tendência em ser superior em esportes, nas brincadeiras e nas brigas. Em geral, a vítima é um indivíduo ou um grupo de indivíduos pouco sociável, costuma possuir um aspecto físico mais frágil e, especialmente entre os meninos, é ineficaz em esportes e possui coordenação motora ineficiente. Vale ressaltar que, em alguns casos, a vítima pode assumir papel de vítima agressora. Por fim, a testemunha é o indivíduo que presencia essas situações, mas não participa diretamente, e adota a lei do silêncio, com medo de possíveis retaliações (FANTE, 2005; LOPES NETO, 2005; SILVA, 2010).

O bullying escolar possui grande prevalência durante a prática de algum tipo de atividade física, seja no recreio, seja nas aulas de Educação Física. Esses são momentos de elevada interação social, facilitando a ocorrência de tal fenômeno (BOTELHO; SOUZA 2007) e, de acordo com Fante e Pedra (2008), a quadra esportiva é um dos principais locais para a ocorrência de bullying dentro da escola.

Especialmente no contexto da Educação Física escolar, devido ao processo histórico vivenciado pela área, o sentimento de exclusão e, consequentemente, casos de bullying dentro das aulas, são explicados devido ao fato de a disciplina possuir um modelo pautado na aptidão física e no alto desempenho, ou seja, a disciplina exige que o aluno utilize toda sua capacidade psicomotora e cognitiva, deixando-o exposto e vulnerável. Sendo assim, os alunos considerados menos habilidosos ou com pior desempenho motor se tornam vítimas em potencial (OLIVEIRA; VOTRE, 2006; BOMFIM et al., 2012).

Com base no exposto, surge o interesse e a necessidade de maior compreensão acerca desse fenômeno, bem como a importância do conhecimento dos profissionais da área, de modo que sejam capazes de identificar, prevenir e intervir nas situações de bullying (ALMEIDA; SILVA; CAMPOS, 2008; FANTE, 2005). Dessa forma, realizou-se estudo com o objetivo de revisar os artigos originais sobre o bullying nas aulas de Educação Física.

\section{Método}

O estudo caracteriza-se como uma revisão sistemática, entendida como um tipo de pesquisa que utiliza como fonte de dados a literatura existente, implicando em uma metodologia rigorosa, planejada, 
explícita e sistematizada, que serve para buscar, identificar, selecionar, caracterizar e analisar estudos sobre determinado tema em questão (SAMPAIO; MANCINI, 2007; DE-LA-TORRE-UGARTE; GUANILO; BERTOLOZZI, 2011).

Esta revisão sistemática versa sobre as investigações primárias do fenômeno Bullying nas aulas de Educação Física. A fim de viabilizar esta investigação, foi elaborada uma ficha de pesquisa (SAURAMARAL, 2011), com o propósito de sistematizar os critérios da revisão sistemática, os termos e o âmbito da pesquisa, bem como definir os critérios de inclusão e exclusão dos artigos.

O estudo abrangeu a busca por artigos de periódicos a partir das bases de dados: Lilacs, Scielo, Medline/EBSCO, Scopus, SPORTDiscus e Web of Science. Utilizou-se, nessa busca, as seguintes equações de pesquisa: Bullying e "Educação Física" (português) Bullying and "phisycal education" (inglês) e Bullying e "Educación Física" (espanhol). Os termos foram combinados por meio do operador boleano " $e$ " ou "and".

O processo de busca nas bases de dados eletrônicas, seleção dos estudos, leitura dos resumos e, posteriormente, dos textos completos, foi realizado pelo investigador principal da pesquisa e por um segundo pesquisador, de maneira simultânea e independente, sem serem identificadas divergências quanto à seleção final dos artigos.

Os critérios de inclusão elencados para esta revisão versaram sobre: (a) artigos originais publicados em periódicos nacionais e internacionais; (b) textos publicados na íntegra; (c) estudos que relacionem, explicitamente, o fenômeno bullying e as aulas de Educação Física. Por conseguinte, foram excluídos desta revisão: (a) artigos de revisão, resumos, resenhas, ensaios teóricos, monografias, dissertações, teses, capítulos ou livros e ponto de vista/opinião de especialistas; (b) artigos sem os textos publicados na íntegra; (c) artigos escritos em outra língua que não o português, o inglês ou o espanhol; d) artigos que não se encaixassem no objetivo desta pesquisa.

O processo de seleção e análise dos artigos que associavam o bullying com as aulas de Educação Física foi realizado em três fases. Inicialmente, fez-se a leitura dos títulos de estudos potencialmente relevantes, em que foram excluídos os que não se adequaram a qualquer um dos critérios de inclusão ou que fossem repetidos. Em um segundo momento, procedeu-se à leitura dos resumos e, por fim, os artigos que atendiam aos critérios de inclusão foram lidos na íntegra, resultando nos artigos que compuseram esta revisão. Assim, das 185 produções inicialmente listadas, 150 foram excluídas na primeira fase (leitura dos títulos), 17 foram excluídas na segunda fase (leitura dos resumos) e 06 foram excluídas na terceira fase (leitura na íntegra), resultando em 12 produções, as quais foram selecionadas e compuseram a presente 
pesquisa. Destaca-se que os artigos escolhidos para esta revisão compreendem estudos publicados em inglês e português.

A análise dos dados compreendeu leitura exploratória e síntese dos artigos completos, seguida de um processo de codificação (BOGDAN; BIKLEN, 1994), por meio do qual foram identificadas palavras, frases e conceitos que representavam elementos comuns, presentes nos diferentes estudos, e permitiram a construção dos códigos e, posteriormente, a aglutinação em categorias (Quadro 1).

Quadro 1 - Categorias e códigos.

\begin{tabular}{|c|c|c|c|c|c|}
\hline \multicolumn{6}{|c|}{ CATEGORIAS } \\
\hline \multirow{7}{*}{$\frac{\mathscr{0}}{0}$} & $\begin{array}{l}\text { Aulas de } \\
\text { Educação } \\
\text { Física }\end{array}$ & $\begin{array}{c}\text { Atividade } \\
\text { Física }\end{array}$ & $\begin{array}{c}\text { Professor de } \\
\text { Educação } \\
\text { Física }\end{array}$ & $\begin{array}{l}\text { Relações } \\
\text { pessoais }\end{array}$ & Bullying \\
\hline & Participação & Aderência & Estratégias & Diferenças & Definição \\
\hline & $\begin{array}{l}\text { Contato } \\
\text { corporal }\end{array}$ & Frequência & Metodologias & Deficiência & Agressor \\
\hline & Competição & Motivação & $\begin{array}{l}\text { Preparo/ } \\
\text { formação }\end{array}$ & Gênero & Vítima \\
\hline & Insatisfação & $\begin{array}{c}\text { Desempenho } \\
\text { Motor }\end{array}$ & $\begin{array}{l}\text { Papel do } \\
\text { professor }\end{array}$ & Preconceito & $\begin{array}{c}\text { Violência } \\
\text { física, verbal } \\
\text { e/ou } \\
\text { psicológica }\end{array}$ \\
\hline & $\begin{array}{c}\text { Práticas de } \\
\text { Bullying }\end{array}$ & $\begin{array}{c}\text { Habilidades } \\
\text { Motoras }\end{array}$ & Apoio & $\begin{array}{c}\text { Composição } \\
\text { Corporal }\end{array}$ & \\
\hline & & & Limitações & & \\
\hline
\end{tabular}

Fonte: Elaboração própria

A partir desse procedimento, foi realizado o cruzamento dos dados advindos das diferentes categorias e de seus respectivos códigos, o que permitiu elencar os seguintes eixos de análise: (1) relações pessoais e Bullying, com ênfase para a compreensão e formas de manifestações desse fenômeno nas aulas de Educação Física; (2) atividade física e Bullying, com destaque para as relações entre a vitimização por 
bullying e o envolvimento/participação nas aulas de Educação Física e/ou Atividade Física; (3) identificação, prevenção, intervenção e Bullying, com foco na discussão do papel do professor e da disciplina de Educação Física, no tocante às situações de bullying no contexto escolar.

\section{Resultados e discussão}

Entre os 12 estudos selecionados, 07 foram realizados no Brasil, 02 nos Estados Unidos, 02 na Suécia e 01 na Itália. O instrumento mais utilizado foi o questionário, seguido pela entrevista e observação e, por fim, somente a entrevista. Nesse sentido, tendo em vista o delineamento dos estudos, predominaram as pesquisas do tipo quantitativo $(n=7)$, enquanto 05 possuem caráter qualitativo.

Embora não tenha sido realizado um recorte temporal na busca pelos artigos, todas as publicações incluídas no presente estudo foram realizadas entre os anos de 2010 e 2015. Esse fato é facilmente explicado por conta do fenômeno se tratar de algo novo do ponto de vista da ciência e, somente nas últimas décadas, torna-se foco dos estudos científicos (FANTE, 2005; LOPES NETO, 2005; SILVA, 2010).

Em relação aos participantes, nota-se que, na maioria das pesquisas, participaram estudantes com idades entre 10 e 19 anos e, de acordo com a literatura, a faixa de idade mais comum para esses comportamentos agressivos está entre 11 e 13 anos (LOPES NETO, 2005; FANTE, 2005). Contudo, destaca-se que, nos estudos nos quais foram incluídos adultos, os participantes responderam um questionário com base em suas épocas escolares. No que tange a ocorrência de bullying, os 12 estudos selecionados constataram a presença do bullying dentro do ambiente escolar e, consequentemente, nas aulas de Educação Física. Desse modo, alguns estudos indicam que episódios de vitimização e/ou assédio são práticas comuns no contexto da disciplina. Os estudos selecionados estão descritos no quadro 2.

Quadro 2 - Estudos analisados sobre bullying e Educação Física escolar.

\begin{tabular}{|c|c|c|c|c|}
\hline $\begin{array}{c}\text { AUTOR/ } \\
\text { ANO }\end{array}$ & TÍTULO & LOCAL & OBJETIVO(S) & METODOLOGIA \\
\hline $\begin{array}{l}\text { Campos; El } \\
\text { Tassa; Cruz } \\
\text { (2015) }\end{array}$ & $\begin{array}{l}\text { Violência escolar: } \\
\text { relações entre } \\
\text { bullying e a } \\
\text { Educação Física. }\end{array}$ & $\begin{array}{c}\text { Ponta } \\
\text { Grossa - } \\
\text { PR-Brasil }\end{array}$ & $\begin{array}{l}\text { Analisar se o bullying pode } \\
\text { ser considerado elemento } \\
\text { responsável pela exclusão } \\
\text { de alunos nas aulas de } \\
\text { Educação Física. }\end{array}$ & $\begin{array}{l}\text { Observação e } \\
\text { entrevista com alunos } \\
\text { do Ensino } \\
\text { Fundamental ( } 8^{\circ} \text { e } 9^{\circ} \\
\text { ano). }\end{array}$ \\
\hline
\end{tabular}




\begin{tabular}{|c|c|c|c|c|}
\hline $\begin{array}{c}\text { Vianna; } \\
\text { Souza; Reis } \\
\text { (2015) }\end{array}$ & $\begin{array}{l}\text { Bullying nas aulas } \\
\text { de Educação Física: } \\
\text { a percepção de } \\
\text { alunos do Ensino } \\
\text { Médio. }\end{array}$ & $\begin{array}{c}\text { Rio de } \\
\text { Janeiro- } \\
\text { RJ-Brasil }\end{array}$ & $\begin{array}{l}\text { Verificar as percepções do } \\
\text { bullying no Ensino Médio. }\end{array}$ & $\begin{array}{c}\text { Questionário } \\
\text { semiestruturado com } \\
\text { perguntas abertas e } \\
\text { fechadas. }\end{array}$ \\
\hline $\begin{array}{c}\text { Barbosa; } \\
\text { Fumes (2014) }\end{array}$ & $\begin{array}{c}\text { O bullying e a } \\
\text { Educação Física } \\
\text { escolar: relatos de } \\
\text { alunos com surdez. }\end{array}$ & $\begin{array}{l}\text { Maceió- } \\
\text { AL-Brasil }\end{array}$ & $\begin{array}{l}\text { Analisar o ponto de vista } \\
\text { da diretora, dos } \\
\text { professores de Educação } \\
\text { Física e dos alunos com } \\
\text { deficiência auditiva de } \\
\text { uma escola para jovens e } \\
\text { adultos, sobre o bullying } \\
\text { nas aulas de Educação } \\
\text { Física Escolar. }\end{array}$ & $\begin{array}{c}\text { Entrevista } \\
\text { semiestruturada. }\end{array}$ \\
\hline $\begin{array}{l}\text { O’ Connor; } \\
\text { Grabe } \\
\text { (2014) }\end{array}$ & $\begin{array}{l}\text { Sixth-Grade } \\
\text { Physical Education: } \\
\text { An Acculturation of } \\
\text { Bullying and Fear. }\end{array}$ & EUA & $\begin{array}{l}\text { Descobrir as percepções de } \\
\text { alunos e professores sobre } \\
\text { o bullying na Educação } \\
\text { Física e sobre o apoio de } \\
\text { seus pares e adultos. }\end{array}$ & $\begin{array}{c}\text { Observação e } \\
\text { entrevista com } \\
\text { estudantes do Ensino } \\
\text { Fundamental. }\end{array}$ \\
\hline $\begin{array}{l}\text { Weimer; } \\
\text { Moreira } \\
(2014)\end{array}$ & $\begin{array}{c}\text { Violência e } \\
\text { bullying: } \\
\text { manifestações e } \\
\text { consequências nas } \\
\text { aulas de Educação } \\
\text { Física Escolar }\end{array}$ & $\begin{array}{l}\text { Cuiabá- } \\
\text { MT-Brasil }\end{array}$ & $\begin{array}{l}\text { Identificar a ocorrência de } \\
\text { situações de violência e } \\
\text { bullying nas aulas de } \\
\text { Educação Física, assim } \\
\text { como o sentimento dos } \\
\text { alunos que vivenciaram } \\
\text { e/ou sofreram com tais } \\
\text { situações durante as aulas. }\end{array}$ & $\begin{array}{c}\text { Entrevista estruturada } \\
\text { com questões abertas e } \\
\text { fechadas. }\end{array}$ \\
\hline $\begin{array}{c}\text { Bejerot et al. } \\
\text { (2013) }\end{array}$ & $\begin{array}{l}\text { Poor motor skills: a } \\
\text { risk maker for bully } \\
\text { victimization }\end{array}$ & Suécia & $\begin{array}{l}\text { Investigar a relação entre } \\
\text { um nível baixo de } \\
\text { habilidades motoras na } \\
\text { infância e o bullying, em } \\
\text { uma população não- } \\
\text { clínica. } \\
\end{array}$ & $\begin{array}{c}\text { Questionário de } \\
\text { Avaliação de } \\
\text { Habilidades Motoras, } \\
\text { Habilidades } \\
\text { Acadêmicas e } \\
\text { Bullying. } \\
\end{array}$ \\
\hline $\begin{array}{l}\text { Linhares; } \\
\text { Farias; Lins } \\
\text { (2013) }\end{array}$ & $\begin{array}{c}\text { O bullying na } \\
\text { Educação Física } \\
\text { Escolar e sua } \\
\text { diferença entre } \\
\text { meninos e meninas. }\end{array}$ & $\begin{array}{l}\text { Itaperuna - } \\
\text { RJ-Brasil }\end{array}$ & $\begin{array}{l}\text { Analisar a relação do } \\
\text { gênero com os tipos de } \\
\text { bullying mais frequentes } \\
\text { nas aulas de Educação } \\
\text { Física Escolar. }\end{array}$ & $\begin{array}{l}\text { Questionário sobre } \\
\text { bullying (Bandeira, } \\
\text { 2009) com alunos do } \\
\text { Ensino Fundamental. }\end{array}$ \\
\hline $\begin{array}{l}\text { Roman; } \\
\text { Taylor } \\
\text { (2013) }\end{array}$ & $\begin{array}{l}\text { A multilevel } \\
\text { assessment of } \\
\text { school climate, } \\
\text { bullying } \\
\text { victmization, and } \\
\text { physical activity. }\end{array}$ & EUA & $\begin{array}{c}\text { Analisar a influência do } \\
\text { bullying e do ambiente } \\
\text { escolar sobre a atividade } \\
\text { física. }\end{array}$ & $\begin{array}{c}\text { Questionário com } \\
\text { estudantes do Ensino } \\
\text { Médio. }\end{array}$ \\
\hline Bomfim et al. & Ocorrência de & Guará-DF- & $\begin{array}{l}\text { Investigar a existência e } \\
\text { sob que forma o bullying }\end{array}$ & $\begin{array}{l}\text { Questionário sobre } \\
\text { bullying - Training }\end{array}$ \\
\hline
\end{tabular}




\begin{tabular}{|c|c|c|c|c|}
\hline (2012) & $\begin{array}{l}\text { bullying nas aulas } \\
\text { de Educação Física } \\
\text { em uma escola do } \\
\text { Distrito Federal. }\end{array}$ & Brasil & $\begin{array}{c}\text { ocorre nas aulas de } \\
\text { educação física em uma } \\
\text { escola do Distrito Federal }\end{array}$ & $\begin{array}{l}\text { Mobility and Research } \\
\text { (TMR) (ORTEGA et. } \\
\text { al., 2000), com } \\
\text { estudantes do Ensino } \\
\text { Fundamental. }\end{array}$ \\
\hline $\begin{array}{l}\text { Scarpa et al. } \\
\qquad(2012)\end{array}$ & $\begin{array}{l}\text { Peer-victimization } \\
\text { during physical } \\
\text { education and } \\
\text { enjoyment of } \\
\text { physical activity. }\end{array}$ & Itália & $\begin{array}{l}\text { Examinar a relação entre a } \\
\text { vitimização entre pares } \\
\text { durante a prática esportiva } \\
\text { e o prazer pela atividade } \\
\text { física. }\end{array}$ & $\begin{array}{l}\text { Questionários }{ }^{3} \text { com } \\
\text { escolares do nordeste } \\
\text { da Itália. }\end{array}$ \\
\hline $\begin{array}{l}\text { Bejerot; } \\
\text { Edgar; } \\
\text { Humble } \\
(2010)\end{array}$ & $\begin{array}{l}\text { Poor performance } \\
\text { in physical } \\
\text { education - a risk } \\
\text { factor for bully } \\
\text { victimization. A } \\
\text { case-control study. }\end{array}$ & Suécia & $\begin{array}{l}\text { Explorar a relação entre } \\
\text { um histórico de } \\
\text { habilidades motoras pobres } \\
\text { na infância e o bullying. }\end{array}$ & $\begin{array}{l}\text { Questionário de } \\
\text { autopercepção, } \\
\text { problemas de } \\
\text { execução, motor e } \\
\text { habilidades } \\
\text { acadêmicas e bullying } \\
\text { com estudantes } \\
\text { universitários. }\end{array}$ \\
\hline $\begin{array}{l}\text { Levandoski; } \\
\text { Cardoso } \\
\text { (2010) }\end{array}$ & $\begin{array}{l}\text { Percepção docente } \\
\text { sobre as relações de } \\
\text { agressividade, o } \\
\text { lúdico e o bullying } \\
\text { na escola. }\end{array}$ & $\begin{array}{c}\text { Ponta } \\
\text { Grossa- } \\
\text { PR-Brasil }\end{array}$ & $\begin{array}{l}\text { Analisar a maneira como } \\
\text { os alunos administram } \\
\text { suas situações de conflito e } \\
\text { verificar a existência do } \\
\text { fenômeno bullying em } \\
\text { escolares. }\end{array}$ & $\begin{array}{c}\text { Observação e a } \\
\text { realização de } \\
\text { entrevista com alunos } \\
\text { do Ensino } \\
\text { Fundamental }\end{array}$ \\
\hline
\end{tabular}

Fonte: Elaboração própria

\subsection{Relações pessoais e Bullying}

Os resultados apontam que, de modo geral, os alunos tendem a associar o bullying com situações de violência, seja ela, física, verbal ou psicológica. Contudo, nota-se que os sujeitos investigados apresentam pouca clareza sobre as consequências causadas pelo envolvimento nessas práticas, decorrentes, sobretudo, do desconhecimento do conceito e/ou significado do termo bullying (WEIMER; MOREIRA, 2014; LEVANDOSKI; CARDOSO, 2010), bem como pela dificuldade de tradução do mesmo para alunos surdos, devido à ausência de um sinal ${ }^{4}$ que representasse o termo (BARBOSA; FUMES, 2014).

Dentre as vítimas de bullying, de acordo com o estudo de Berjerot et al. (2013), o nível socioeconômico, o desempenho acadêmico e a composição corporal são fatores que influenciam

3 PACES: Physical Activity Enjoyment Scale (KENDZIERKI; DE CARLO, 1991) e MPVS: Multidimensional PeerVictimization Scale (MYNARD; JOSEPH, 2000).

${ }^{4}$ LIBRAS: Língua Brasileira de Sinais. 
diretamente o envolvimento nos casos de intimidação. Tais resultados corroboram com o estudo de O'Connor e Grabe (2014), que apontam qualidades físicas, percebidas como diferentes, enquanto estimuladoras do surgimento dos episódios de bullying.

No estudo de Barbosa e Fumes (2014), os participantes relataram sofrer bullying durante todas as suas trajetórias escolares e, em geral, os episódios estavam relacionados à sua deficiência auditiva, em que os agressores exteriorizavam atitudes preconceituosas, principalmente através de apelidos pejorativos atribuídos a sua condição linguística. Desse modo, o bullying não se trata somente de uma expressão de violência qualquer, sem um fator determinante, ou seja, tem sua representação intimamente ligada ao conceito de preconceito, especialmente em relação aos fatores sociais que determinam os grupos que serão vitimizados (ANTUNES; ZUIN, 2008).

Quanto às manifestações do bullying nas aulas de Educação Física, os estudos apontam que o fenômeno ocorre tanto de forma direta quanto indireta. No primeiro caso, o tipo de bullying mais praticado é o verbal (WEIMER; MOREIRA, 2014; BARBOSA; FUMES, 2014; VIANNA; SOUZA e REIS, 2015). Já nos casos de bullying indireto, a violência do tipo psicológica é a principal manifestação do fenômeno (LINHARES; FARIAS e LINS, 2013; BEJEROT; EDGAR e HUMBLE, 2010). Por sua vez, a pesquisa desenvolvida por Bomfim et. al. (2012) não identificou diferenças significativas entre as formas de manifestação do bullying entre escolares.

Nota-se, assim, que o bullying se manifesta predominantemente pela forma não física, fato que, de acordo com O’Connor e Grabe (2014), acaba fazendo com que as aulas de Educação Física se tornem um momento propício às práticas de bullying no contexto escolar, uma vez evidenciada a tendência do professor da disciplina de intervir somente nas situações que envolvem agressão física, ignorando outros tipos de manifestações e fazendo com que estas se tornem naturalizadas.

As relações de gênero também aparecem como uma variável dos estudos que investigam o fenômeno bullying nas aulas de Educação Física. Nesse sentido, o estudo de Linhares, Farias e Lins, (2013) não apontou diferenças significativas em relação ao gênero, contudo, quando comparadas meninas e meninos, as meninas são mais frequentes vítimas $(68,8 \%)$ e testemunhas $(68,2 \%)$ e meninos agressores $(64,7 \%)$ e vítimas/agressoras $(44,0 \%)$. Os dados também apontam que, dentre os agressores, as meninas afirmam serem vitimizadas por meninas e também meninos, enquanto os estudantes do sexo masculino somente por outro menino. Entretanto, as meninas tendem a persuadir mais outros estudantes para praticar o bullying.

Nesta direção, os estudos evidenciam que o sexo masculino é uma das características predominantes dos agressores e, na percepção masculina, a agressão física é mais comum que a 
emocional, enquanto na visão feminina ocorre o inverso (VIANNA; SOUZA; REIS, 2015); os sujeitos do sexo masculino tendem a se envolver mais em situações de violência (WEIMER; MOREIRA, 2014); e meninos são considerados mais agressivos se comparados às meninas (LEVANDOSKI; CARDOSO, 2010). Ao encontro desses resultados, a literatura também identifica que a maioria dos agressores é do sexo masculino (MENEGOTTO; PASINI; LEVANDOWSKI, 2013; FANTE, 2005; SILVA, 2010; ALMEIDA; CARDOSO; COSTAC, 2009; OLIVEIRA; VOTRE, 2006).

A questão do gênero perpassa as aulas de Educação Física, também devido aos estereótipos esperados de cada sexo, construídos histórica e socialmente, nos quais se espera que as meninas sejam frágeis e meigas e meninos necessitem demonstrar agressividade (OLIVEIRA; VOTRE, 2006).

Outro aspecto presente nessa categoria é o impacto do bullying na participação dos alunos nas aulas de Educação Física. Os achados do estudo de Campos, El Tassa e Cruz (2015) indicam que o bullying não foi o motivo pelo qual as alunas deixaram de participar das aulas, uma vez que alegaram motivos relacionados à saúde, cansaço e dores nas pernas. Todavia, no estudo de Vianna, Souza e Reis (2015), aproximadamente 16\% dos entrevistados revelam que algum colega ou ele próprio já deixou de participar das aulas de Educação Física em decorrência do bullying. Já no estudo de Roman e Taylor (2013), os indivíduos vitimizados praticavam menos dias de Educação Física, enquanto na pesquisa de O'Connor e Grabe (2014), os resultados indicam que os estudantes vitimizados gostariam de não participar das aulas.

\subsection{Atividade física e Bullying}

Dos 12 artigos analisados, cinco discutem de modo mais específico a relação entre o bullying, a prática da atividade física e habilidades motoras. Tais estudos revelam que alunos sofredores de bullying podem se envolver menos em práticas de atividades físicas, bem como indivíduos com habilidades motoras e desempenho nas aulas de Educação Física abaixo da média possuem mais chances de sofrer bullying. Por outro lado, os estudos não confirmam se o bullying é o fator responsável por prejudicar o desenvolvimento motor dos indivíduos ou se o não envolvimento em atividades físicas leva à vitimização, o que sugere a necessidade de ampliação de estudos para identificar essa possível correlação (MEDEIROS, ZEQUINÃO; CARDOSO, 2014).

De acordo com o estudo de Roman e Taylor (2013), os alunos que relataram ter sido vítima de bullying apresentavam menor frequência nas aulas de Educação Física e menor tendência de se envolver em atividade física em mais de um dia, por 60 minutos ou mais. De acordo com os estudos de Bejerot et. 
al. (2013) e Bejerot, Edgar e Humble (2010), respectivamente, 48,5\% e 57\% dos participantes que relataram um histórico de habilidades motoras pobres na infância foram vitimizados em comparação com $25,2 \%$ e $26 \%$ dos participantes que afirmaram possuir, pelo menos, um nível mediano. Ou seja, indivíduos de um nível considerado inferior de habilidades motoras possuem chances consideravelmente maiores de se tornarem vítimas de bullying, quando comparados aos indivíduos supostamente mais habilidosos.

Indo ao encontro desses resultados, ao examinar a relação entre a vitimização por pares, durante a prática esportiva e o prazer pela atividade física, o estudo de Scarpa et. al. (2012) identificou sutis associações entre essas variáveis, de modo que as crianças com menos sucesso no esporte tendem a apresentar menos prazer pela atividade física. Entretanto, não se pode afirmar que a vitimização por bullying durante a atividade física pode influenciar negativamente o prazer pela mesma, pois fatores intrínsecos do indivíduo podem ser mais relevantes nesse contexto. Ademais, os estudos de O’Connor e Grabe (2014) e Bejerot, Edgar e Humble (2010) enfatizam que os casos de agressão nas aulas de Educação Física estão relacionados às habilidades das vítimas, de modo que um desempenho abaixo da média nesta disciplina apresenta-se como um fator de risco relevante de tornar-se vítima.

Esses resultados associam-se à literatura, quanto ao fato de os estudantes poderem ser vitimizados, caso não demonstrem desempenho nas aulas de Educação Física à altura das expectativas neles depositadas, principalmente entre alunos do sexo masculino (OLIVEIRA; VOTRE, 2006). Nesse sentido, as vítimas costumam dispor de rendimento baixo em lutas e esportes, devido à coordenação motora pouco desenvolvida, ao contrário dos agressores, que tendem a ser mais fortes e possuir desempenho melhor nas atividades físicas (BOTELHO; SOUZA, 2007; FANTE, 2005; SILVA, 2010; LOPES NETO, 2005).

\subsection{Prevenção, identificação, intervenção e Bullying}

Tendo em vista os prejuízos causados pela exposição dos indivíduos ao bullying, os artigos analisados ainda ressaltam a importância e a necessidade de se identificar manifestações desse fenômeno no contexto escolar, bem como discutir iniciativas de prevenção e/ou intervenção, através da participação conjunta de toda a comunidade escolar. Assim, identificar as situações de bullying e classificar os envolvidos deve ser considerado somente o primeiro passo, pois, a partir do momento em que se faz um diagnóstico do problema, é desencadeada uma sensação ilusória de controle sobre os fatos (ANTUNES; ZUIN, 2008). 
Além disso, mesmo sabendo da natureza social do problema e, por isso, de responsabilidade de todos, os professores esperam que a própria escola tome alguma providência e esta, por sua vez, não realiza nenhuma grande intervenção nesse sentido (BARBOSA; FUMES, 2014). Predomina, também, a ideia de que os professores e funcionários da escola devem intervir impedindo atos agressivos. Contudo, o estudo de Levandoski e Cardoso (2010) constata a existência da tendência dos professores nas aulas de Educação Física em limitar as possibilidades dos alunos identificarem e gerenciarem situações de conflito, a fim de evitar e controlar o contato corporal.

Nota-se, ainda, no estudo de Weimer e Moreira (2014), o discurso, assumido pelos alunos, de insatisfação para com as aulas e professores de Educação Física, assim como no estudo de Bomfim et al. (2012), ao constatar um baixo índice $(2,1 \%)$ de alunos intimidados que já teriam pedido ajuda a um adulto.

O estudo de O'Connor e Grabe (2014) concorda ser comum a ausência de procura dos alunos por ajuda de um adulto, principalmente por medo, e aponta que as seleções curriculares dos professores de Educação Física funcionam como agentes catalisadores de episódios de bullying, uma vez que preconizam atividades competitivas. Esses resultados corroboram com a literatura existente, uma vez que atribuem o fato de o fenômeno comumente não ser percebido com facilidade, pois a vítima tende a não relatar o que lhe ocorre por temer as consequências (FANTE, 2005; LOPES NETO, 2005).

Logo, os professores possuem um papel de extrema importância na elaboração de estratégias e de metodologias, para que as relações no ambiente escolar sejam saudáveis e favoreçam o desenvolvimento dos alunos, e, devido à proximidade com os estudantes, os docentes podem identificar mais facilmente situações de bullying (MENEGOTTO; PASINI; LEVANDOWSKI, 2013). Especialmente na Educação Física, Botelho e Souza (2007) entendem que o professor deve iniciar estratégias para o combate desse problema ainda na Educação Infantil, e essas ações devem acompanhar os estudantes durante todas as etapas da Educação Básica e, além disso, serem incluídas como conteúdo específico das aulas de Educação Física.

Assim, considera-se, a Educação Física uma disciplina com características que, se não forem bem administradas, podem favorecer o surgimento de casos de violência, pois aulas que enfatizam a competição e a rivalidade podem gerar comportamentos violentos entre os alunos (PRODÓCIMO et al., 2012). Sobretudo, a Educação Física tem muito a colaborar na prevenção e no combate ao bullying através dos conteúdos que lhe são atribuídos, por exemplo. É o caso dos jogos de caráter cooperativo, em que os participantes jogam somente pelo prazer proporcionado pela prática em si, e a superação de 
desafios é realizada em conjunto com os outros (e não contra os outros), ou seja, a pressão de competir não é priorizada, vislumbrando a integridade de todos (BROTTO, 2001).

\section{Considerações finais}

A revisão de artigos sobre bullying nas aulas de Educação Física permitiu verificar a prática como comum no contexto escolar e nas aulas de Educação Física. Todavia, observou-se um entendimento raso dos sujeitos investigados acerca do conceito do fenômeno, tampouco do conhecimento dos problemas causados em decorrência da exposição dos envolvidos a essa violência.

Constatou-se que alunos sofredores de bullying tendem a praticar menos atividade física e, nesse sentido, indivíduos considerados menos habilidosos e com um desempenho abaixo da média nas aulas de Educação Física, são mais propensos a serem vitimizados. Sendo assim, alguns aspectos que diferenciam uns alunos específicos da maioria, podem ser fatores agravantes no surgimento de casos de vitimização, como um nível socioeconômico baixo, obesidade e alguma deficiência, por exemplo. Observou-se, ainda, um impacto direto entre o bullying e a participação dos alunos nas aulas de Educação Física, no qual alunos vitimizados tendem a não participar das aulas. Embora o bullying seja uma prática recorrente em ambos os sexos, em geral, os estudos apontam que meninos são mais agressivos e envolvem-se mais nesses casos, se comparado às meninas.

Os estudos também destacam a relevância do professor e da disciplina de Educação Física no enfrentamento dessa problemática nas escolas, através da identificação e intervenção nos casos de bullying, tendo em vista que, comumente, as manifestações desse fenômeno ocorrem de maneira velada, e as vítimas tendem a não relatar o que ocorre aos professores e, por isso, a percepção dessas situações se torna difícil. Desse modo, o professor pode elaborar estratégias e metodologias que visem eliminar ou, pelo menos, diminuir a incidência dessas ocorrências.

A escassez de literatura sobre a temática pode ser considerada uma limitação da presente investigação, sobretudo no tocante à correlação entre o bullying e as aulas de Educação Física, sugerindo a necessidade de adensamento nas investigações acerca dessa temática. Ademais, estudos com maior transversalidade poderiam auxiliar de forma mais concreta no combate ao bullying, fazendo com que as ações de prevenção e intervenção sejam mais eficazes. Nesse aspecto, conclui-se que é preciso analisar e compreender o fenômeno de maneira mais abrangente, possivelmente por meio da utilização de metodologias qualitativas, para, então, explorar o fenômeno a partir de diversos pontos de vista. 


\section{Referências}

ALMEIDA, S. B.; CARDOSO, L. R. D; COSTAC, V.V. Bullying: Conhecimento e prática pedagógica no ambiente escolar. Psicologia Argumento, Curitiba, v. 27, n. 58, p. 201-206, jul./set. 2009.

ANTUNES, D.C.; ZUIN, A.A.S. Do bullying ao preconceito: os desafios da barbárie à educação. Psicologia e Sociedade, Florianópolis, v. 20, n.1, p. 33-42, 2008.

BOMFIM, D. L. et al. Ocorrência de bullying nas aulas de Educação Física em uma escola do Distrito Federal. Pensar a prática, Goiânia, v. 15, n. 2, p. 272-550, abr./jun., 2012.

BOTELHO, R. G.; SOUZA, J. M. C. Bullying e Educação Física na escola: características, casos, consequências e estratégias de intervenção. Revista de Educação Física, v. 139, p. 58-70, 2007.

BROTTO, F. O. Jogos cooperativos: o jogo e o esporte como um exercício de convivência. Santos: Projeto Cooperação, 2001.

DE-LA-TORRE-UGARTE, M. C.; GUANILO, R. F. T.; BERTOLOZZI, M. R. Revisão sistemática: noções gerais. Revista da Escola de Enfermagem, São Paulo, v. 45, n. 5, p. 1260-6, 2011.

FANTE, C. Fenômeno bullying: como prevenir a violência e educar para a paz. São Paulo: Verus, 2005.

FANTE, C.; PEDRA, J. A. Bullying Escolar: perguntas e respostas. Porto Alegre: Artmed, 2008.

ALMEIDA, L. K.; SILVA, A. C.; CAMPOS, J. S. Importância da identificação precoce da ocorrência do bullying: uma revisão de literatura. Revista Pediatria, v. 9, n. 1, p. 8-16, jan./jun. 2008.

LOPES NETO, A. A. Bullying: comportamento agressivo entre estudantes. Jornal de Pediatria, Rio de Janeiro, n. 81, supl. 5, p. 164-172, 2005.

MEDEIROS, P.; ZEQUINÃO, M. A.; CARDOSO, F. L. Bullying e a relação entre atividade física e coordenação motora: uma revisão sistemática. Cinergis, Santa Cruz do Sul, v. 15, n. 3, out., 2014.

MENEGOTTO, L. M. O.; PASINI, A. I.; LEVANDOWSKI, G. O bullying escolar no Brasil: uma revisão de artigos científicos. Psicologia: Teoria e Prática, São Paulo, v.15, n. 2, p. 203-215, maio/ago., 2013.

OLIVEIRA, W. A. et. al. Interfaces entre família e bullying escolar: uma revisão sistemática. Psico-USF, Bragança Paulista, v. 20, n. 1, p. 121-132, jan./abr. 2015.

OLIVEIRA, F. F; VOTRE, S. J. Bullying nas aulas de educação física. Movimento, Porto Alegre, v. 12, n. 2, p.173-197, 2006.

PRODÓCIMO, E. et. al. Produções acadêmicas sobre violência, agressão e agressividade em periódicos brasileiros de Educação Física. Pensar a Prática, Goiânia v. 17, n. 3, p. 682-700, jul./set., 2014.

SAMPAIO, R. F.; MANCINI, M. C. Estudos de revisão sistemática: um guia para síntese criteriosa da evidência científica. Revista Brasileira de Fisioterapia, São Carlos, v. 11, n. 1, p. 83-89, jan./fev. 2007.

SAUR-AMARAL, I. Revisão sistemática da literatura com apoio de Endnote X4 e NVIVO 9. Aveiro: GOVCOPP, 2011 
SILVA, A. B. B. Mentes perigosas nas escolas. Rio de Janeiro: Objetiva, 2010.

SPOSITO, M. P. Um breve balanço da pesquisa sobre violência escolar no Brasil. Educação e Pesquisa, USP, v. 27, n. 1, p. 87-103, 2001.

\section{Como citar este artigo}

FUCHS, F.; FOLLE, A.; BENITES, L. C.; DUEK, V. P. Bullying e Educação Física escolar: uma revisão da produção científica. Revista Kinesis, Santa Maria, v. 39, p. 01-15, 2021.

* O presente trabalho não contou com apoio financeiro de nenhuma natureza para sua realização 